\title{
Imaging characterization of friction stir welds in the AA 5182-H111 aluminium alloy
}

Rui M. Leal ${ }^{*, * *}$, Carlos Leitão *, Altino Loureiro *, Dulce M. Rodrigues *

* CEMUC - Department of Mechanical Engineering, University of Coimbra, Rua Luís Reis Santos, Pinhal de Marrocos, 3030-788 Coimbra, Portugal

** ESAD.CR-IPL Rua Isidoro Inácio Alves de Carvalho, 2500-321 Caldas da Rainha dulce.rodrigues@dem.uc.pt

The environmentally friendly friction stir welding (FSW) process is being increasingly used in joining similar and dissimilar aluminium and copper alloys and other soft materials. In this process a rotating tool promotes significant shear strain and frictional heating of the base materials, in order to stir them into a highly plasticized weld region, at the trailing side of the tool.

Due to the intense plastic deformation, complex material flow patterns, such as vortices, swirls and whorls $[1,2]$ occur during welding. In dissimilar welds, these patterns are readily revealed by differential etching and the respective microstructures characterized. However, in similar welds, such as the welds between plates of AA 5182-H111 aluminium alloy, it is hard to distinguish the different features in the welds and characterize their microstructures. Fig. 1 illustrates optical and TEM micrographs of a weld in this alloy. In the optical image of the weld, at the top of the image, it is possible to distinguish three main areas signalized by numbers: the weld nugget (1), with a very fine grain structure with $2.8 \mu \mathrm{m}$ mean grain size, and a transition region (2) between the nugget and the base material (3), which is usually called the Thermomechanical Affected Zone (TMAZ). During welding, due to the intense plastic deformation characteristic of the FSW process, and the rise in temperature in the weld area, which can be of the order of $0.8 \mathrm{~T}_{\mathrm{m}}$, severe microstructural changes occur in the weld nugget and in the TMAZ. These microstructural changes can be understood by comparing the micrographs of the unaffected base material with that from the nugget and from the transition zone.

In fact, the AA 5182-H111 material is a non heat treatable aluminium alloy for which the grain size and strain hardening are key factors conditioning the mechanical strength $[2,3]$. In order to illustrate this, the grain size in the nugget and base material are compared at the top of the figure. Differences in dislocation density in the different weld regions can also be depicted by comparing the TEM images presented in the figure. In fact, the H111 condition of the base material indicates that this alloy is only slightly strain hardened, which is evidenced by the presence of dislocation walls only at the grain boundaries. In the TMAZ, the grains are absent of dislocations as a result of recovery resulting from heating occurring during the weld process. Finally, in the weld nugget, where plastic deformation and heating are occurring simultaneously, a very fine grained structure with a high density of dislocations is discernible in the TEM images of this zone. This TEM results allows explaining the differences in mechanical properties between the Nugget and the base material depicted in [3]. In fact, the FS weld obtained in the AA 5182-H111 show overmatched mechanical properties, relative to the base material.

\section{References:}

[1] J. van der Geer, J.A.J. Hanraads, R.A. Lupton, J. Sci. Commun. 163 (2000) 51.

[2] W. Strunk Jr., The Elements of Style, third ed., Macmillan, New York, 1979.

[3] C. Leitão, R.M. Leal, D.M. Rodrigues, A. Loureiro, P. Vilaça. Mat. Design 30 (2009) 101. 

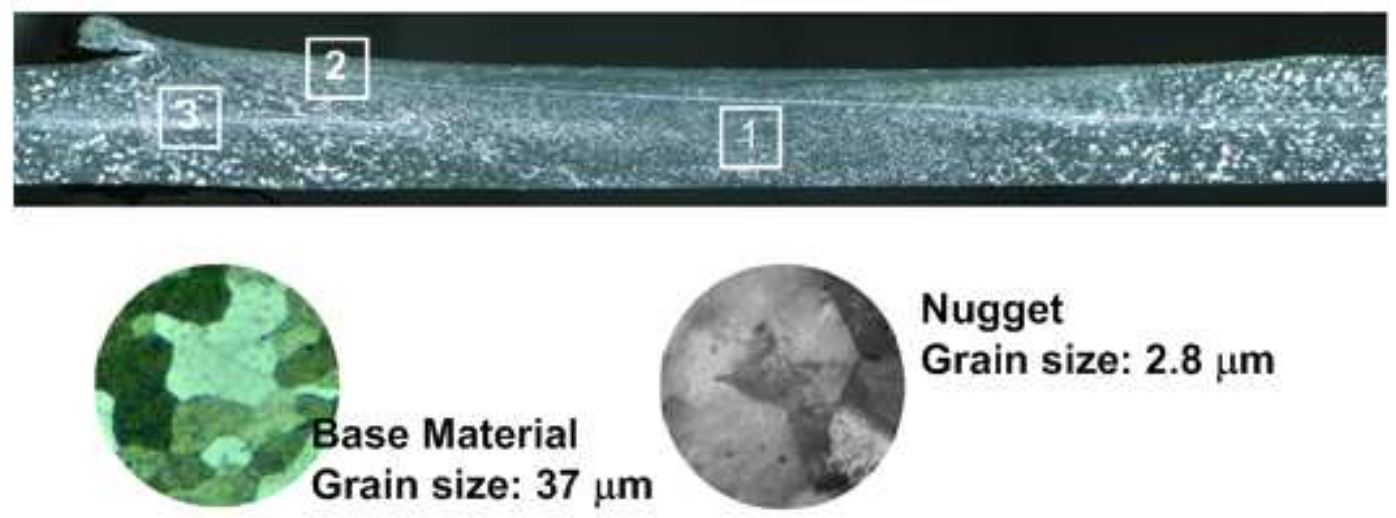

Nugget

Grain size: $2.8 \mu \mathrm{m}$
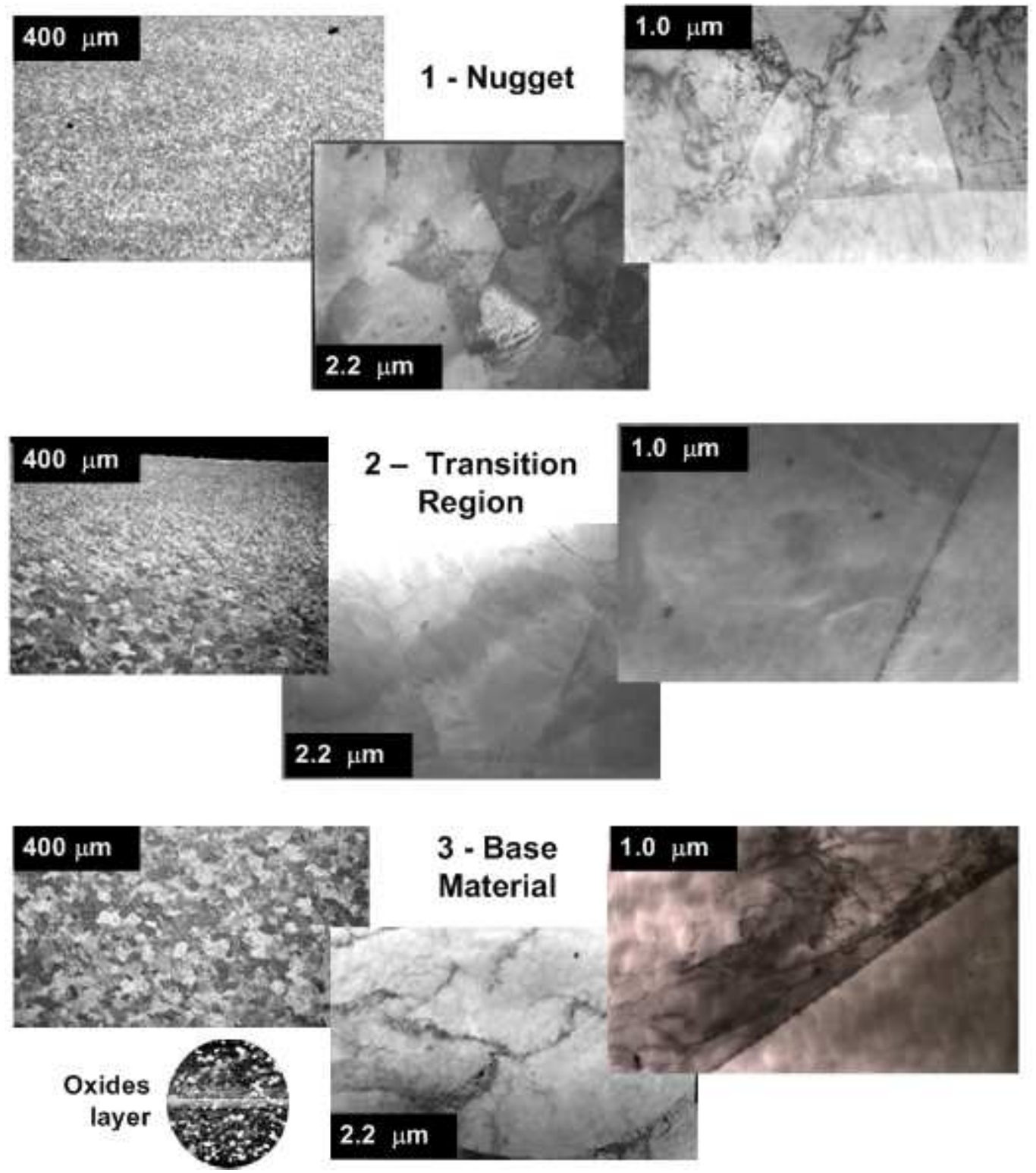

Figure 1 - Optical and TEM micrographs of various zones of a friction stir weld. 